\title{
PERFIL DA MORTALIDADE MATERNA EM MATERNIDADE PÚBLICA DE TERESINA - PI, NO PERÍODO DE 1996 A 2000: UMA CONTRIBUIÇÃO DA ENFERMAGEM
}

\author{
Maternal Profile Mortality in a Public Maternity of Teresina - PI (Brazil), \\ in the Period between 1996 and 2000: a Nursing Contribution \\ Perfil de la Mortalidad Materna en la Maternidad Pública de Teresina - PI (Brasil), \\ en el Periodo de 1996 a 2000: una Contribución de la Enfermería
}

Francisca Maria do Nascimento
Regina Luzia Alencar Bezerra

\author{
Maria de Fátima Sá Dantas \\ Inez Sampaio Nery
}

\begin{abstract}
Resumo
Estudo quantitativo retrospectivo com objetivo de caracterizar o perfil da mortalidade materna em uma maternidade pública de Teresina-PI, no período de 1996 a 2000. 0 universo constou de 107 óbitos maternos, cujos instrumentos foram: prontuários, declarações dos óbitos, livro de registros e relatórios da enfermagem, coletados em setembro a dezembro de 2004 em formulário estruturado. Os dados relativos aos aspectos socioeconômicos e pessoais revelaram como procedência os Estados: Piauí (73), 33 da capital e 40 de outras cidades; Maranhão (33); e Pará (1). A maioria das mulheres era casada, tinha idade entre 20 e 30 anos, um a três filhos, ensino fundamental incompleto e era do lar. Os dados obstétricos na maioria revelaram a não-realização de seis consultas pré-natais, era a primeira gravidez, parto cesariano e admissão em estado grave. Destacaram-se como causas dos óbitos: infecções, hipertensão e hemorragias. Conclui-se que a mortalidade materna é problema grave, necessitando melhoria assistencial nos serviços de saúde.
\end{abstract}

Palavras-chave: Enfermagem. Mortalidade Materna. Saúde da Mulher.

\begin{abstract}
Cuantitative and retrospective study that objectified to demonstrate the maternal mortality profile of a public maternity in Teresina - PI (Brazil), in the period between 1996 and 2000. The universe was composed by 107 maternal deaths, whose used instruments had been: medical record, declaration of death, book of register and nursing report, collected in September to December in a structuralized form. The related data to the social, economic and personal aspects had disclosed as origin states: Pará (01), Maranhão (33) and Piauí (73) of these 33 from Teresina and 40 from other cities. The majority of women were married, between 20 and 30 years old, with one to three children, incomplete basic education, and housewives. The obstetrics data had demonstrated that the majority did not carry through six prenatal consultations, were in the first pregnancy, cesarean childbirth and admitted in serious condition. As frequent causes of the deaths they had been distinguished: infections, hypertension and hemorrhages. It was concluded that the maternal mortality it is a serious problem, that needs improved assistance in the health.
\end{abstract}

Keywords: Nursing. Maternal Mortality. Women's Health.

\section{Resumen}

Estudio cuantitativo y retrospectivo, que objetivó caracterizar el perfil de la mortalidad materna de una maternidad pública en Teresina - PI (Brasil), en el periodo de 1996 hasta 2000. El universo fue compuesto por 107 muertes maternas, cuyos instrumentos fueron: prontuarios, declaración de muertes, libros de registros y relatos de la enfermería, colectados en septiembre y diciembre de 2004 en formulario estructurado. Los datos relativos a los aspectos socioeconómico y personales revelaran como origen los Estados: Pará (01), Maranhão (33) y Piauí (73) de estos 33 de Teresina y 40 del interior. La mayoría de las mujeres era casada, tenía edad entre 20 y 30 años, de uno a tres niños, la educación básica incompleta, trabajadoras del hogar. Los datos de la obstetricia habían demostrado que la mayoría no realizaron seis consultas prenatales, estaban en el primer embarazo, parto cesariano y admitido en estado serio. Fueran destacadas como causas frecuentes de las muertes: infecciones, hipertensión y hemorragias. Concluyese que la mortalidad materna es un grave problema, necesitando mejoría de la ayuda en los servicios de salud.

Palabras clave: Enfermería. Mortalidad Materna. Salud de la Mujer. 
INTRODUÇÃO

Para milhares de mulheres o nascimento de uma criança, celebrado universalmente, não é motivo de comemoração, nem tampouco é vivenciado como um acontecimento maravilhoso, mas como um inferno particular que pode terminar em morte.

Num contexto relacional, a gravidez pode estar marcada por carinho, amor, compreensão ou também pela rejeição, desamor e mesmo violência. Cada gravidez é única, e pode desencadear reações de aceitação ou rejeição nas mulheres, parceiros, familiares ou até na comunidade. Assim, a evolução da gravidez, o parto e o puerpério são incógnitas, mas passíveis de intervenções convenientes ${ }^{1}$.

A morte materna decorrente da gestação é considerada "um desastre, um acontecimento desnecessário, uma perda com enorme sentimento de tristeza e dor, causando uma sensação de crueldade pelas mortes, as quais não deveriam ocorrer, principalmente se a mulher não está doente"2-8.

Para conceituar morte materna é necessário desconsiderar as que são provocadas por fatores acidentais ou incidentais, passando a ser conceituada como "a morte de uma mulher durante a gestação ou até 42 dias após o término da gestação, independente da duração ou da localização da gravidez"3-8.

A morte materna é certamente um indicador síntese das condições socioeconômicas de um país e da qualidade de vida da população. Expressa a desvalorização e 0 desrespeito à vida, o que é traduzido na prestação de uma assistência desumana e de baixa qualidade. A mortalidade materna também aponta a "determinação política" de um país na realização de "ações coletivas e socializadas"4.

A morte materna é uma tragédia ainda ignorada, pois as vítimas são pessoas desprezadas, que possuem pouca influência junto aos recursos financeiros da nação. Estudos internacionais indicam que nos lugares onde os índices de mortalidade materna são altos, os serviços de saúde são grosseiramente inadequados em quantidade e qualidade ${ }^{3}$.

Ressalta-se a importante afirmação do ex-ministro da saúde José Serra quando enfatiza que para evitar os altos índices de morte materna, as mulheres precisam de livre acesso com segurança no ato de parir, com atendimento emergencial de qualidade nos casos obstétricos, garantindo assim os "direitos reprodutivos", bem como a cidadania das mulheres brasileiras ${ }^{3}$.

Os aspectos mais simples da obstetrícia não estão sendo diagnosticados, porque os profissionais apóiam-se demasiadamente na tecnologia ou mesmo porque não são realizados alguns procedimentos que sempre foram feitos. Isso demonstra a necessidade imediata de revisão do ensino nas escolas médicas e de Enfermagem, uma vez que não se necessita de grandes aparatos tecnológicos, visto que é possível resolver $70 \%$ a $80 \%$ dos casos com atendimento simplificado 5 .

Outros fatores registrados são: 0 alto índice de pobreza, a falta de acesso às informações, negligência e ausência de serviços de saúde adequados, e ainda a considerável multiparidade na mulher associada à submissão em relação ao parceiro ${ }^{5}$.
A Organização Mundial de Saúde estimou que, em 1990, morriam anualmente em todo o mundo aproximadamente 585.000 mulheres, por complicações ligadas ao ciclo gravídico puerperal, e que destas $5 \%$ residiam em países desenvolvidos.

Nas Américas, ao se analisarem as razões da mortalidade materna, torna-se evidente a disparidade entre países desenvolvidos e em desenvolvimento. Em países como Canadá e Estados Unidos, a ocorrência dos óbitos maternos é de 4 a 9 por 100.000 nascidos vivos, enquanto que, em países como a Bolívia, Peru e Haiti, chega a ser mais de 200 óbitos. Entretanto, países considerados economicamente semelhantes aos demais países da América Latina, tais como Chile, Cuba, Costa Rica e Uruguai, apresentam coeficientes de morte materna bem inferior, menos de 40 por 100.000 nascidos vivos ${ }^{4}$.

De acordo com o Departamento de Informática do Sistema Único de Saúde - SUS, observa-se a Razão da Mortalidade Materna - RMM de 58,56 em 1999 e 47,36 em 2000. Já a RMM, nos anos de 2001 e 2002, ficou estimada em 69,19 óbitos maternos por 100.000 nascidos vivos no Brasil ${ }^{6}$.

Em 1998, a razão de mortalidade materna no Brasil a partir dos óbitos declarados foi de 64,8 óbitos por 100.000 nascidos vivos. Nas regiões Norte, Nordeste e Centro-Oeste foram $57,1,56,1$ e 54,8 por 100.000 nascidos vivos, respectivamente. As regiões Sudeste e Sul apresentaram, respectivamente, 76,2 e 70,1 por 100.000 nascidos vivos ${ }^{4}$.

Nos países em desenvolvimento, a mortalidade materna tem sido de difícil monitoramento por conta de dois fatores: a subinformação e sub-registro das declarações de óbito. As causas para esse problema estão vinculadas à existência de cemitérios clandestinos, ocorrências de partos domiciliares em áreas rurais sem a devida assistência, dificuldade de acesso a cartórios, à ignorância quanto à importância do atestado de óbito e ao preenchimento inadequado de declarações ${ }^{4}$.

No Piauí, a prevenção da mortalidade materna começou através de ações dos comitês: estadual, regional e interhospitalares. Porém, com as dificuldades relacionadas ao subregistro de nascidos vivos, bem como ao preenchimento inadequado das fichas de notificação e declaração de morte materna, o qual favorece o elevado percentual de informações ignoradas, não se tem um indicativo da realidade piauiense ${ }^{7}$.

Com base na problemática em estudo, não é mais admissível em pleno século XXI a contabilização de tantos óbitos relacionados com a reprodução humana e de certa forma levados pelo sentimento humanitário, próprio da profissão de enfermagem.

Neste sentido, este estudo teve por objetivos: caracterizar o perfil dos óbitos maternos ocorridos de 1996 a 2000 em uma maternidade pública de Teresina-PI; identificar as causas que levaram ao óbito materno; e analisar os fatores de risco que contribuíram para os óbitos na instituição.

Esta pesquisa oferecerá subsídios para elaboração de medidas preventivas na redução dos óbitos e também contribuirá como reflexão para que a morte passe a ser encarada como fato possível de intervenções convenientes das equipes que lidam com essa mulher, conseqüentemente influenciará na redução dos coeficientes relativos aos óbitos maternos na instituiçã̃o em estudo. 


\section{MATERIAL E MÉTODOS}

Trata-se de uma pesquisa retrospectiva, realizada em uma maternidade pública de Teresina-Pl, referente aos óbitos maternos ocorridos de 1996 a 2000. Os dados foram coletados entre os meses de setembro e dezembro de $2004 \mathrm{e}$ teve o livro de registro dos óbitos da maternidade a parte inicial na obtenção dos dados que continham informações dos 107 óbitos maternos. Utilizaram-se ainda 90 prontuários disponíveis, livros e relatórios de enfermagem dos vários setores por onde as mulheres estiveram internadas. Vale ressaltar que 17 prontuários não foram localizados, e que os dados obtidos decorreram das referidas fontes de informações. Essa pesquisa foi realizada com $100 \%$ dos óbitos maternos ocorridos no período estudado, ou seja, a sua totalidade.

Os dados foram coletados através de um formulário estruturado após pré-teste de acordo com a Declaração de Óbito, o qual contemplou tópicos básicos e variáveis indispensáveis à pesquisa. Essa coleta transcorreu com análise detalhada das fontes, procurando estabelecer relações entre as variáveis desde a admissão da mulher até o óbito. Foi solicitada previamente a autorização da instituição para a realização da pesquisa, seguindo os aspectos éticos com base na Resolução 196/96 do Conselho Nacional de Saúde - CNS, com consentimento pela direção da maternidade da assinatura do termo.

A consolidação final dos dados foi registrada num formulário final de resultados adaptado para este fim, seguida da tabulação dos dados, cujos resultados foram interpretados e apresentados em tabelas com freqüências e percentuais, bem como discutidos com base na literatura sobre o tema.

\section{RESULTADOS}

Os resultados deste estudo compreenderam coeficientes de mortalidade materna; aspectos pessoais, socioeconômicos e culturais; condições obstétricas, gestão hospitalar; causas não obstétricas e obstétrica direta e indireta; fatores de risco e a assistência prestada às 107 mulheres que morreram.

\section{a) Coeficiente de Mortalidade Materna - CMM e procedência:}

0 CMM oscilou ano a ano conforme seqüência para 100.000 nascidos vivos (NV). Observaram-se os seguintes coeficientes, em 1996 - 162,9; 1997 - 127,9; 1998 243,0; 1999 - 148,8; e 2000 - 169,5. Estas oscilações foram decorrentes tanto do numerador (número de óbitos maternos), quanto do denominador (número de nascidos vivos), em que se verificou um ligeiro decréscimo ano a ano, fato que contribuiu para o CMM médio do período equivaler a 170,8 para 100.000 nascidos vivos.

Quanto à procedência, o Piauí teve a participação de 13 óbitos maternos em 1996; 9 em 1997; 21 em 1998; 17 em 1999 e 13 em 2000; no entanto, os óbitos procedentes do Maranhão foram 8 óbitos maternos em 1996; 7 em 1997; 9 em 1998 e 9 em 2000, e apenas um óbito procedente do Pará.

\section{b) Aspectos pessoais, socioeconômicos e culturais:}

Quanto à faixa etária, 24,3\% (26) dos óbitos ocorreram em mulheres de 19 a 24 anos; $18,7 \%$ (20) referentes às de 25 a 29 anos; em menores de 19 anos foi de 15,9\% (17); na faixa etária de 30 a 40 anos foi de $14,0 \%$ (15) e nas mulheres acima de 39 anos foi de $13,1 \%$ (14). A faixa que menos ocorreu óbito foi entre 35 e 39 anos, com 9,3\% (10).

Em relação ao estado civil, constatou-se que ocorreram mais óbitos entre as mulheres casadas, ou seja, 38,8\% (41); as solteiras foram 17,8\% (19); e as mulheres que viviam em união estável representaram 16,8\% (18) dos óbitos.

No que se refere à escolaridade, 29,0\% (31) possuíam o Ensino Fundamental incompleto; 14,0\% (15) eram analfabetas; 2,8\% (3) concluíram Ensino Médio; 2,8\% (3) tinham Ensino Médio incompleto e 0,9\% (1) possuía Ensino Superior.

Quanto à renda familiar, 6,6\% (7) apresentavam renda entre um e dois salários mínimos (SM); 0,9 (1), renda entre quatro e nove SM; 0,9 (1), renda familiar entre 10 e 12 SM; e somente 2,9\% (2) possuíam renda superior a 13 SM.

No que tange à ocupação/profissão, 52,4\% (56) eram do lar; 2,9\% (3) eram lavradoras; 0,9\% (1) era estudante e 0,9\% (1) era funcionária pública estadual.

Vale destacar os altos índices das variáveis sem informaç̧ões, como o preenchimento inadequado dos prontuários e outros documentos hospitalares que foram bastante significativos para os dados referentes à renda familiar (88,8\%), ocupação $(42,9 \%)$, escolaridade $(34,6 \%)$ e estado civil $(27,1 \%)$.

\section{c) Óbitos maternos, segundo os dados obstétricos:}

Das 107 mulheres que faleceram, 29,0\% (31) realizaram menos que seis consultas no pré-natal; $17,8 \%$ (19) não realizaram o pré-natal; $12,1 \%$ (13) realizaram mais de seis consultas, enquanto $41,1 \%$ (44) não continham informações. Em relação ao número de gestações, 37,4\% (40) engravidaram de duas a quatro vezes; $23,0 \%$ (25) estavam grávidas pela primeira vez; 14,0\% (15) engravidaram de 5 a 7 vezes; 10,3\% (11) tiveram mais de 8 gestações; de 14,9\% (16) não se tinha informação.

Quanto ao número de filhos, 33,6\% (36) das mulheres tinham de 1 a 3 filhos; $21,5 \%$ (23) não tinham filhos; $18,0 \%$ (15) tinham de 4 a 8 filhos; 4,7\% (5) tinham mais de 9 filhos e de $26,2 \%$ (28) não se tinha informação.

No que diz respeito ao período gravídico puerperal em que as mulheres foram admitidas, $45,8 \%$ (49) estavam grávidas no terceiro trimestre; $15,0 \%$ (16), no puerpério tardio; $13,1 \%$ (14) estavam grávidas no segundo trimestre; 9,3\% (10), respectivamente, no primeiro trimestre e no puerpério imediato; e de 7,5\% (8) não se tinha informação. Quanto ao quadro clínico na admissão, 37,4\% (40) estavam em estado grave; $29,0 \%$ (31), em condições regulares; $28,0 \%$ (30), em estado de coma; e 5,6\% (6), em estado bom ou ótimo.

Quanto ao diagnóstico realizado na admissão, 36,5\% (39) tinham doenças hipertensivas específicas da gravidez (DHEG); 19,6\% (21), fraco trabalho de parto; 13,1\%, (14), infecção; 9,3\% (10), hemorragia, e 1,9\% (1) era cardiopata.

Quanto às condições do feto, 36,5\% (39) nasceram vivos; $15,0 \%$ (16) morreram antes do trabalho de parto e $12,0 \%$ 
(13), no intra-parto. Quanto ao tipo de gravidez, 62,6\% (67) era de um único feto; 2,8\% (2), gravidez gemelar; 4,6\% (5) era com mola hidatiforme e gravidez anembrionada.

\section{d) Gestão hospitalar:}

Quanto à permanência hospitalar: 54,3\% (58) morreram nas primeiras 24 horas; $14,0 \%$ (15) faleceram no segundo dia de internação; $13,0 \%$ (14) foram a óbito no terceiro dia de internação; 9,3\% (10), entre 8 e 14 dias; e 8,5\% (9), no período de 3 dias. Somente uma foi a óbito após 15 dias de internação. Já quanto à referência hospitalar: 42,2\% (46) foram admitidas procedentes de hospital do interior; 9,3\% (10) vieram encaminhadas pelo hospital local; 13,0\% (14), diretamente do domicílio; 16,8\% (18), sofreram reinternação por algum tipo de infecção; de 16,8\% (18) não se tinha informação, e apenas 0,9\% (01) era procedente de posto de saúde.

Quanto às intervenções realizadas, 34,0\% (36) sofreram parto operatório; $26,1 \%$ (28), parto normal; $14,0 \%$ (15), tratamento clínico; 10,2\% (11) realizaram histerectomia; e $8,4 \%$ (9), curetagem. Destacam-se ainda que 3,7\% (4) sofreram laparotomia exploradora. Em relação ao local de ocorrência do parto, 51,4\% (55) dos partos ocorreram na maternidade; $23,4 \%$ (25) não pariram; $18,7 \%$ (20) do partos ocorreram no hospital da cidade de origem; $2,8 \%$ (3), em domicílio, e de 3,7\% (4) não se tinha informação.

Em relação às causas básicas da morte materna, foram: 29,9\% (32) infecções; 28,0\% (30) doenças hipertensivas especificas da gravidez (DHEG); $21,5 \%$ (23) hemorragias; $16,8 \%$ (18) outras causas; $1,9 \%$ (2) das causas relacionaramse a distúrbios tromboembolíticos e 1,9\% (2), a cardiopatias. Observou-se, portanto, que 67 dos óbitos foram por causas obstétricas diretas e 40 por causas obstétricas indiretas.

\section{e) Óbitos maternos segundo registro de assistência prestada}

No que diz respeito ao registro no prontuário das mulheres que foram a óbito, em 51,4\% (55), a anamnese estava incompleta; em 22,4\% (24), a anamnese estava completa, e em $26,2 \%$ (28), não havia registro.

Quanto à assistência ao trabalho de parto, durante e na primeira hora pós-parto, observou-se que 4,6\% (5) evoluíram no trabalho de parto, sendo acompanhadas através do partograma; 70,8\% (75) foram avaliadas sem o partograma. Os registros da pressão arterial $(\mathrm{PA})$ no trabalho de parto, durante e na primeira hora pós-parto, demonstraram que, das 65 mulheres que pariram, 43,1\% foram acompanhadas com esse controle e 56,9\% não apresentaram registro da PA.

\section{DISCUSSÃO}

0 Ministério da Saúde, embora tenha investido em várias áreas de assistência à mulher, tem verificado poucas mudanças no contexto social em favor da saúde feminina, já que a mulher ainda é vista como "objeto" e submetida à violência física, psicológica e sexual

Os coeficientes de mortalidade materna na instituição pesquisada demonstraram que há ineficiência na qualidade dos serviços de saúde na assistência à saúde da mulher em idade fértil, deixando muito a desejar. Esses coeficientes apresentaram oscilações moderadas com exceções de 1998.

Os serviços de atenção à saúde da mulher em Teresina-PI funcionam precariamente, exigindo uma boa estrutura física, bom gerenciamento e recursos materiais e humanos com qualidade e quantidade adequadas. Isso seguramente possibilitaria um melhor atendimento à mulher, e, conseqüentemente, a mortalidade materna no município de Teresina não apresentaria uma significativa elevação no número de óbitos em relação aos anos anteriores (127,9/ $100.000 \mathrm{NV}$ ) e posteriores (148,8/100.000 NV). Em 1998, - Coeficiente de Mortalidade Materna (CMM) foi de 243,0/ 10.000 em relação a 1997, aumentou consideravelmente.

Este aumento foi decorrente do número de mulheres provenientes das várias cidades do Piauí, inclusive da capital, e verificou-se certa estabilidade relacionada à demanda de mulheres provenientes de outros estados, demonstrando que a enorme demanda piauiense de gestantes de alto risco gestacional, principalmente da capital, funcionou como fator determinante para o que foi constatado.

Em 1999, o CMM foi de 148,8/100.000 NV, apresentou um significativo decréscimo em relação ao ano anterior. $\mathrm{Na}$ avaliação dos gestores da instituição em estudo, foi atribuído à diminuição na demanda de mulheres oriundas de cidades de outros Estados, o que é passível de acatamento, levando-se em consideração os implementos de portarias do Ministério da Saúde em favor da saúde da mulher e da família, inclusive legislação especifica relativa à atuação da enfermeira obstetra na realização do pré-natal, assistir ao parto normal e melhorar a assistência puerperal.

Para intervir na questão relacionada ao Piauí, a Secretaria de Saúde do Estado realizou a Análise Situacional do Setor Saúde, envolvendo as 17 diretorias regionais. 0 objetivo era suscitar as possibilidades de avanço nas intervenções do Sistema único de Saúde - SUS no Estado do Piaú, pois a descentralização não se faz de um ano para outro, nos municípios, devido às desigualdades na capacidade gerencial dos gestores, e deve ser monitorada com apoio do nível federal e estadual ${ }^{8}$.

A demanda de gestantes de alto risco funcionou como determinante para os coeficientes verificados. 0 CMM é um importante indicador de saúde das mulheres em idade fértil e da qualidade da assistência ao processo reprodutivo. Como fatores contributivos para a ocorrência de tantos óbitos maternos, destacaram-se os antecedentes socioeconômicos e obstétricos, altos índices de parto cesariano e pré-natal de baixa qualidade. Ressalta-se, que para o combate da mortalidade materna, é necessária a assistência ao pré-natal de boa qualidade e a criteriosa assistência durante o parto e puerpério ${ }^{9}$.

Quanto ao Estado do Piauí, a demanda das mulheres da capital foi determinante para o aumento significativo no número de óbitos, pois as outras cidades do Piauí contribuíram com menos de $50 \%$. Acredita-se que a implementação das ações colocadas em prática no momento sob várias vertentes da promoção de saúde à mulher poderá vir a influenciar na diminuição dos coeficientes de mortalidade materna nos próximos anos.

Discutir os fatores que contribuem para as oscilações verificadas nos coeficientes em estudo é tarefa extremamente 
delicada. Simples é acatar a afirmação do ex-ministro da Saúde ao referir que $a$ assistência às mulheres durante o parto e 0 nascimento com segurança e dignidade é compromisso fundamental. 0 Programa de Humanização no Pré-natal e no Nascimento (PHPN) apresenta os princípios da assistência a ser prestada e a exorta dos estados, dos municípios e dos serviços de saúde para o cumprimento de suas funções, a fim de propiciar às mulheres o direito de cidadania que é "dar à luz", através de uma "assistência humanizada e de boa qualidade"4.

Observa-se que a predominância dos óbitos ocorreu na faixa etária de 19 a 29, período em que oferece um menor risco para mulher gestante. Isso demonstra a importância da mortalidade materna para a saúde pública, reforçando a necessidade de uma melhor assistência pré-natal, ao parto e puerpério, bem como da detecção precoce das gestações de riscos; entretanto, entende-se que, por ser esta faixa de maior atividade reprodutiva, é aceitável que as falhas assistenciais sejam mais freqüentes devido ao universo de mulheres ser maior ${ }^{10}$.

Nos casos analisados, a maior incidência aconteceu entre mulheres casadas ou que tinham companheiros, mas foi relevante também entre as solteiras, o que mais uma vez comprova que a gestação de um modo geral implica risco em qualquer situação conjugal.

Verificou-se, ainda, que a grande maioria das mulheres era analfabeta ou não completaram o ensino fundamental, e que a renda familiar não ultrapassava três salários mínimos, a ocupação da maioria era do lar e procediam de cidades do interior.

Nesse sentido, observa-se que, além da idade, a baixa renda familiar, o baixo nível educacional são reconhecidamente fatores de riscos que contribuem para a mortalidade materna, sendo estes resultados condizentes com o de outros estudos; contudo, não se torna isento o poder público da parcela de responsabilidade sobre esta problemática ${ }^{11}$

Quanto aos dados obstétricos, constatou-se que a maioria das mulheres não prestou informação ou realizaram menos que seis consultas pré-natais, o que é um indicativo da desinformação quanto à importância de um pré-natal de qualidade, tendo em vista que através dele se pode prevenir a maioria das complicações das gestações ${ }^{12}$.

Atualmente as famílias brasileiras estão reduzidas em decorrência do processo de transição demográfica, e, por isso, poucas mulheres têm prole acima de três filhos, o que justifica a menor freqüência de óbitos maternos entre as mulheres com prole maior e o maior número de óbitos ter ocorrido nas mulheres com um a três filhos. Neste sentido, também tem se observado a diminuição da taxa de fecundidade e a conquista das mulheres acerca dos direitos sexuais e reprodutivos.

Neste sentido, é lamentável o número de mulheres que vivenciou sua primeira gestação e que não conseguiu a concretização da felicidade que é ser mãe. Comparando o número de filhos com o número de gestações, observou-se certa incoerência entre o número de filhos vivos e número de gestações, o que demonstra que várias dessas mulheres engravidaram e não conseguiram levar a gravidez a termo. A maioria das mulheres foi admitida no terceiro trimestre gestacional ou no puerpério tardio, períodos gestacionais em que mais ocorreram as complicações da doença hipertensiva específica da gravidez (DHEG) e infecções, respectivamente.
As DHEG constituem a principal causa de morte no Brasil e sua etiologia ainda é desconhecida. Aspectos imunológicos genéticos e falhas na placentação são atualmente aceitos unanimemente. A fisiopatologia da doença envolve lesão endotelial difusa, comprometendo a integridade do sistema vascular, a produção de vasos dilatadores endógenos e a manutenção da anticoagulação, produzindo freqüentemente danos aos rins e sistema nervoso central, fígado e placenta; como resultado, as pacientes apresentam envolvimento de múltiplos órgãos com diferentes graus de gravidades ${ }^{13}$.

As infecções relacionadas à gestação dividem-se em grupos de infecção direta e indireta; assim sendo, as diretas relacionadas ao abortamento, choque séptico e infecção puerperal são mais facilmente preveníveis, uma vez que as ocorrências dessas infecç̃oes estão relacionadas a fatores maternos, educacional, assistencial e hospitalar, onde infelizmente é preponderante a ocorrência relacionada a infecções hospitalares ${ }^{13}$.

As infecções indiretas relacionadas à gravidez são basicamente de etiologia infecciosa, causada por agentes microbianos. Os agravos geralmente detectados foram: má assistência obstétrica com lacerações e iatrogenias do canal do parto, práticas indiscriminadas de toques vaginais, trabalhos de partos prolongados, desobediência às técnicas de controle de infecções e, por fim, as operações cesarianas. Todos os agravos provocados devem ser combatidos pelos programas de saúde hospitalar e, ainda, se relacionar ao controle de infecção hospitalar, como ficou comprovado com a observação dos resultados de pneumonia (13), hepatite (3), tuberculose, calazar, dengue e meningite ${ }^{13}$.

Foi evidente a constatação do quadro clínico em que essas pacientes foram admitidas; a maioria deu entrada em estado grave ou coma, casos em que muitas vezes a equipe de saúde já não tem mais tempo para intervir, uma vez que a maioria morre no primeiro dia de hospitalização.

Quanto ao diagnóstico de entrada, o maior índice incidiu sobre aquelas que apresentavam a DHEG, infecções e hemorragias. Mais foi visto também que 21 mulheres foram admitidas apresentando-se bem no trabalho de parto e, sem qualquer complicação, infelizmente morreram vítimas de complicações hemorrágicas surgidas no transcurso e no pós-parto, como se observou no aumento de percentual relacionado à hemorragia.

No ato da admissão, a maioria das mulheres deu entrada apresentando gravidezúnica e com o feto vivo, mas infelizmente alguns fetos foram a óbito no transcorrer do parto. Vale citar três casos de gravidez gemelar, nos quais o óbito ocorreu com o binômio mãe e filho.

Alguns casos de morte podem ser atribuídos ao descaso da própria paciente na procura do atendimento de saúde ou por problemas de transporte, falta de tempo, entre outros. Entretanto, nem sempre a paciente é responsável pela morte ou pela busca tardia da assistência. Os serviços em alguns momentos não percebem a gravidade do caso, assumindo uma conduta expectante que tem a morte como conseqüência ${ }^{12}$.

Com isso, a distribuição dos óbitos maternos, segundo a gestão hospitalar, revela que a permanência hospitalar da maioria das mulheres ocorreu menos de 24 horas, o que indica atraso na busca de atendimento. A precariedade de funcionamento desses serviços, somada muitas vezes à 
incapacidade de um diagnóstico correto, no ato da admissão, favoreceu a evolução do caso para o óbito.

As Instituições de Saúde que assistem a saúde da mulher em Teresina-PI apresentam problemas, tais como a estrutura física, o gerenciamento, carência de recursos materiais e humanos com qualidade e quantidade. Se estes itens fossem politicamente resolvidos com segurança, a assistência à mulher no município de Teresina estaria em melhores condições que as atuais ${ }^{14}$.

Outro fator a ser analisado é a referência hospitalar, já que a maioria das mulheres foi admitida com encaminhamento de hospital do interior, tendo sido submetida a alguma intervenção hospitalar na cidade de origem. Destacam-se ainda os casos de reinternação, em que as mulheres foram assistidas e infelizmente retornaram com algum tipo de complicação muitas vezes conseqüente da internação hospitalar.

A operação cesariana continua a ser a intervenção cirúrgica mais realizada neste serviço, e é relevante o número de outras intervenções realizadas em conseqüência de parto cesárea; entre elas destacam-se a histerectomia e a laparotomia exploradora, muitas vezes realizadas em conseqüência das complicações do parto cesário.

Quanto aos partos normais, observou-se uma quantidade significativa, embora a humanização do parto ainda não seja uma atividade rotineira na instituição em estudo, e é importante ressaltar que a assistência hospitalar ao parto normal deve ser segura e garantida para cada mulher. Os benefícios dos avanços científicos devem permitir e estimular o exercício da cidadania feminina, resgatando a autonomia da mulher no parto ${ }^{15}$.

A classificação das causas da morte materna em obstétrica direta e indireta favorece a identificação das mortes evitáveis, uma vez que as causas diretas são mais facilmente resolvidas por serem conseqüentes do estado gestacional. Constatou-se que as causas básicas de óbito mais freqüentes foram as infecções seguidas das toxemias gravídicas.

Quanto à assistência prestada à parturiente na admissão e durante o transcurso do parto, destacam-se aquelas prioritárias e indispensáveis, e observou-se que o exame clínico obstétrico realizado na admissão, tais como a anamnese (história) da parturiente, o registro da verificação de pressão arterial e a assistência de enfermagem foram realizados de forma inadequada, conforme os resultados. Todos eles, na grande maioria, foram realizados de modo incompleto, o que demonstra a necessidade de melhor qualificação dos profissionais responsáveis pela admissão da parturiente ${ }^{3}$.

Cabe aqui esclarecer que os procedimentos ditos não humanizados são posturas muitas vezes desnecessárias e danosas que deveriam ser evitadas, mas que continuam a fazer parte do dia-a-dia da maioria das maternidades do Brasil ${ }^{16}$.

Quanto aos registros durante o transcurso do parto, os resultados demonstraram a gravidade do quadro, pois, das pacientes que pariram, somente três foram avaliadas com base no partograma, as demais não tiveram essa assistência registrada ou não foram avaliadas. Sendo o partograma um gráfico onde são anotadas a progressão do trabalho de parto e as condições da mãe e do feto, é um instrumento básico da moderna obstetrícia que associa a simplicidade do manejo a uma utilidade prática sem precedentes ${ }^{17}$.

Uma experiência realizada pela OMS na Indonésia, Malásia e Tailândia constatou a efetividade e o baixo custo da realização do partograma. Nesse estudo, a proporção do trabalho de parto superior a 18 horas caiu pela metade, após a implantação do partograma e o índice de cesarianas que foi reduzido em quase $50 \%$. Portanto, o partograma corretamente utilizado melhora o acompanhamento do trabalho de parto e do final da gestação; assim sendo, toda a rede hospitalar vinculada ao SUS deverá ter como rotina a prática obrigatória do preenchimento do partograma no prontuário da gestante ${ }^{15}$.

\section{CONSIDERAÇÕES FINAIS}

As mulheres que foram ao óbito em sua maioria residiam na zona urbana das cidades piauienses ou na capital; estavam com idade entre 19 e 29 anos; a maioria era casada; eram semialfabetizadas e domésticas; percebiam de 1 a 3 salários mínimos.

A ineficácia do preenchimento dos prontuários das mulheres que foram ao óbito e a constatação de registros incompletos sem as informações necessárias dificultaram a coleta dos dados. Contudo, os dados obstétricos analisados revelaram que essas mulheres realizaram menos que 6 consultas de prénatal, 2 a 4 gestações e 1 a 3 partos; foram admitidas no terceiro trimestre da gravidez em quadro clínico grave ou muito grave, com diagnóstico de infecção ou DHEG, e a maioria com o feto vivo. A permanência hospitalar foi de até 24 horas com procedência do interior ou da maternidade em estudo.

A assistência prestada às mulheres na admissão da anamnese, do exame clínico obstétrico e da assistência de enfermagem ocorreu de forma incompleta, e não se registrou a pressão arterial, sendo avaliada na sala de parto aleatoriamente. Todavia, embora se constate a necessidade de ações rotineiras e preventivas como essas, pôde-se evidenciar, a partir de registros, as causas dos óbitos, que em sua maioria foi em conseqüência de infecção, doença hipertensiva específica da gravidez e hemorragia.

Com base nos resultados, sugere-se que haja treinamento e capacitação para os médicos, enfermeiras e pessoal de nível médio em enfermagem que assistem à mulher no pré-natal na admissão, tratamento clínico, sala de parto e puerpério, bem como para estudantes de medicina, enfermagem e outros; aumento de enfermeiros na Instituição; inclusão de enfermeiras obstétricas na escala para trabalho de equipe com médicos plantonistas; estruturação e funcionamento de uma comissão de controle de morte materna que venha a atender as exigências nessa área e que seja realmente de qualidade na realização da Vigilância Epidemiológica do óbito materno na Instituição.

Fazem-se necessários a construção e a instalação de uma Unidade de Terapia Intensiva materna de alta complexidade com pessoas capacitadas para atendimento de qualidade; aumento de recursos humanos qualitativa e quantitativamente para reestruturação das equipes médicas e de enfermagem; estímulo aos profissionais quanto ao registro e preenchimento adequado dos documentos hospitalares referentes à cliente; a implantação e implementação da assistência humanizada à gestante parturiente e puérpera, a qual deverá ser praticada por todos os profissionais que atendam a mulher; os recursos materiais e os técnicos adequados para o bom funcionamento das equipes da maternidade; e que a maternidade assuma realmente o seu caráter de hospital de referência prestando uma assistência mais qualificada à sua clientela. 


\section{Referências}

1. Ministério da Saúde(BR)Atenção integral à saúde:1999 a 2000. Brasília(DF); 1999.

2. Laurenti R. A mortalidade materna e o município. Brasília(DF: Ministério da Saúde; 1995.

3. Ministério da Saúde(BR). Gestação de alto risco. Brasília(DF); 2002.

4. Ministério da Saúde (BR).. Manual dos comitês de mortalidade materna. Brasília(DF); 2002

5. Araújo MJO.Campanha Internacional contra a morte materna completa 13 anos. Jornal da Rede Saúde 2000 maio; ( 20): 3-4.

6. Ministério da Saúde (BR). Rede Intergerencial de Informações para Saúde. Indicadores de mortalidade. Brasília(DF); 2004.

7. Secretaria do Estado de Saúde(PI). $3^{\circ}$ Seminário de Mortalidade Materna. Teresina(PI); 2002.

8. Barros ME. Análise situacional do setor de saúde no Estado do Piaúí. RASPP- Rev Assoc Saúde Pública de Piauí 1998 dez.; 1 (2):189-216

9 Gomes KRO. Mortalidade materna em maternidade escola do município de Teresina-PI. In: Resumos do $3^{\circ}$ Congresso Brasileiro dos Conselhos de Enfermagem-CBCEnf. Rio de Janeiro(RJ);2000.

10. Ferreira G, et al. Mortalidade materna no Ceará. Rev Bras Ginec Obst Atual 1996; 9:13.

11. Theme Filha MM., Silva RI, Noronha CP. Mortalidade materna no município do Rio de Janeiro: 1993 a 1996. Cad Saude Publica 1999;15: 397- 403.

12. Tanaka ACA. Maternidade: dilema entre nascimento e morte. São Paulo(SP): Hucitec/ ABRASGO; 1996.

13. Zugaib M, et al. A mortalidade materna. J Bras Ginec 2000; ( 95): 129.
14. Nery IS, Sá MIMR. Avaliação do atendimento á mulher na rede pública de saúde em Teresina-PI, na perspectiva dos profissionais da área. In: Desafios de identidade, espaço-tempo de mulher. Belém(PA): CEJUSP, 1997, p.409-430.

15. Ministério da Saúde (BR). Parto, abor to e puerpério: assistência humanizada à saúde. Brasília(DF); 2003.

16. Bicchieri T, Silva LR. A percepção dos acadêmicos de enfermagem sobre o cuidado à mulher no trabalho de parto enascimento: uma abordagem qualitativa. Esc Anna Nery. Rev Enferm 2006 ago; 10(2): 258-65.

17. Baracat E. Partograma: procedimento essencial em obstétrica. Rev Med Conselho Federal, 2000 abr; 15 (116): I

\section{Sobre as Autoras}

\section{Francisca Maria do Nascimento}

Enfermeira da Maternidade Dona Evangelina Rosa, Especialistas em Enfermagem Obstétrica.

\section{Maria de Fátima Sá Dantas}

Enfermeira da Maternidade Dona Evangelina Rosa, Especialistas em Enfermagem Obstétrica.

\section{Regina Luzia Alencar Bezerra}

Enfermeira da Maternidade Dona Evangelina Rosa, Especialistas em Enfermagem Obstétrica.

\section{Inez Sampaio Nery}

Professora Adjunto IV, Sub- Coordenadora do Mestrado em Enfermagem e chefe do Departamento de Enfermagem da UFPI, Doutora em Enfermagem. 